\begin{tabular}{ccc}
\hline Bentham OPen & The Open Biomedical Engineering & $\begin{array}{l}\text { The } \\
\text { Biomedical } \\
\text { Enginecing } \\
\text { lournal }\end{array}$ \\
\hline CrossMark & Content list available at: www.benthamopen.com/TOBEJ/ & DOI: $10.2174 / 1874120701610010062$ \\
\hline
\end{tabular}

RESEARCH ARTICLE

\title{
Factors Affecting Lethal Isotherms During Cryoablation Procedures
}

\author{
Andrew C. Rau ${ }^{1, *}$, Ryan Siskey ${ }^{1}$, Jorge A. Ochoa ${ }^{2}$ and Tracy Good ${ }^{3}$ \\ ${ }^{\text {I}}$ Exponent, Inc., 3440 Market Street, Suite 600, Philadelphia, PA 19104, United States \\ ${ }^{2}$ Exponent, Inc., Menlo Park, CA, United States \\ ${ }^{3}$ Product Development, Healthtronics, Inc., Austin, TX, United States
}

Received: March 18, 2016

Revised: June 02, 2016

Accepted: June 07, 2016

\begin{abstract}
:
Background:

Creating appropriately-sized, lethal isotherms during cryoablation of renal tumors is critical in order to achieve sufficiently-sized zones of cell death. To ensure adequate cell death in target treatment locations, surgeons must carefully select the type, size, location, and number of probes to be used, as well as various probe operating parameters.
\end{abstract}

\section{Objective:}

The current study investigates the effects of probe type, operating pressure, and clinical method on the resulting sizes of isotherms in an in vitro gelatin model.

\section{Method:}

Using a total of four cryoprobes from two manufacturers, freeze procedures were conducted in gelatin in order to compare resulting sizes of constant temperature zones (isotherms). The effects of certain procedural parameters which are clinically adjustable were studied.

\section{Results:}

Test results show that the sizes of $0{ }^{\circ} \mathrm{C},-20{ }^{\circ} \mathrm{C}$ and $-40{ }^{\circ} \mathrm{C}$ isotherms created by similarly-sized probes from two different manufacturers were significantly different for nearly all comparisons made, and that size differences resulting from changing the operating pressure were not as prevalent. Furthermore, isotherm sizes created using a multiple freeze procedure (a ten minute freeze, followed by a five minute passive thaw, followed by another ten minute freeze) did not result in statistically-significant differences when compared to those created using a single freeze procedure in all cases.

\section{Conclusion:}

These results indicate that selection of the probe manufacturer and probe size may be more important for dictating the size of kill zones during cryoablation than procedural adjustments to operating pressures or freeze times.

Keywords: Cryoablation, In vitro gelatin model, Lethal Isotherms, Probes, renal tumors.

\section{INTRODUCTION}

Cryoablation has become increasingly popular as a primary treatment for small tumors in multiple clinical applications, including treatment of renal lesions [1 - 3]. While partial excision remains a commonly used technique, minimally invasive laparoscopic cryoablation and percutaneous cryoablation, in general, have gained popularity as an alternative to open surgery [4]. Advances in imaging technologies have provided real-time imaging of surgical sites and contributed to the efficacy of the cryoablation as a treatment technique [1]. Treatment of tumors via cryosurgery has 


\begin{abstract}
* Address correspondence to this author at the Exponent, Inc., 3440 Market Street, Suite 600, Philadelphia, PA 19104, USA; Email:arau@exponent.com
\end{abstract}

been shown to be effective within a variety of tissue types, including treatment of tumors in kidney, liver, prostate, and lung tissue [5 - 10]. Treatment of renal cancer using cryoablation has been successful, and clinical follow-up data indicates that cryoablation of renal neoplasms can be effective and lead to long term patient survival $[4,11]$. In order to cause complete cell death, sufficiently low ablation temperatures must be achieved. While a complete consensus regarding the in vivo temperatures necessary to cause complete cell death in renal tissue has not been reached, lethal temperatures for various tissues have been reported between $-20^{\circ} \mathrm{C}$ and $-40{ }^{\circ} \mathrm{C}[12,13]$. Furthermore, $-20^{\circ} \mathrm{C}$ has been shown to destroy renal tissue in both in vivo and in vitro conditions $[4,14]$. Consequently, larger tumors can be ablated using a probe which can produce a larger lethal zone, and the size of the lethal zone produced by a probe is indicative of the freezing power of that probe. In clinical practice, the use of multiple probes to ablate a single tumor may be required if the size of the lethal zone is not sufficient to fully ablate the target tumor. The purpose of this study was to compare isotherm size differences in gelatin compared between probe manufacturers, input gas pressure, and freezing methodology.

\title{
2. MATERIALS AND METHODS
}

Two device designs of different sizes from each of two different manufacturers, identified as Manufacturer A and Manufacturer B, were tested. Device sizes were selected for relevant comparison between manufacturers. Probe designs designated as $1.7 \mathrm{~mm}$ and a $2.4 \mathrm{~mm}$ diameters were tested from Manufacturer A, while the Manufacturer B probe diameters tested were $17 \mathrm{G}(1.47 \mathrm{~mm})$ and $2.4 \mathrm{~mm}$. All testing was conducted in a gelatin medium (Type B, Lot: J44591, J.T. Baker) contained in a $2000 \mathrm{~mL}$ glass beaker and maintained at $20 \pm 1{ }^{\circ} \mathrm{C}$ prior to testing. For each test, the probe was inserted into the gelatin to a nominal depth of $115 \mathrm{~mm}$ and the appropriate freeze procedure was conducted. For single freeze tests, a single ten minute freeze at an operating pressure of $3200 \mathrm{psi}$ was conducted. For multiple freeze tests, an initial ten minute freeze was conducted, followed by a five minute passive thaw, followed by another ten minute freeze. During both freeze steps, the probe was actively cooled for ten minutes by Argon gas at a pressure of $3000 \mathrm{psi}, 3200 \mathrm{psi}$, or $3450 \mathrm{psi}$, and active cooling of the system was disabled during the passive thaw steps. Operating pressures were selected based on manufacturer specifications and common ranges used during clinical procedures [15].

For each test condition, the size of the $0{ }^{\circ} \mathrm{C}$ isotherm was determined by directly measuring the height and diameter of the frozen gelatin using Vernier calipers (Series 500, Mitutoyo, Kawasaki, Japan). For the $-20{ }^{\circ} \mathrm{C}$ and $-40{ }^{\circ} \mathrm{C}$ isotherm size measurements, type $\mathrm{T}$ thermocouples (Omega Engineering) were placed along the length of the probe and at fixed distances from the probe along the location of maximum isotherm diameter. The location of each thermocouple tip was recorded prior to the freeze cycles, and the temperature at the end of the second freeze cycle was recorded. Thermocouple placements were adjusted until the temperature at the end of the second freeze cycle was measured to be within $\pm 1{ }^{\circ} \mathrm{C}$ of the $-20^{\circ} \mathrm{C}$ or $-40^{\circ} \mathrm{C}$ isotherm. The upper, lower, and outer location of each isotherm was defined by the measured location of the thermocouple tip during the final reading. For each test group, three samples of each probe type were fully characterized for $0{ }^{\circ} \mathrm{C},-20{ }^{\circ} \mathrm{C}$, and $-40{ }^{\circ} \mathrm{C}$ isotherm sizes. The experimental setup implemented for testing is shown in Fig. (1), and a summary of sample sizes for all test groups is provided in Table $\mathbf{1}$.

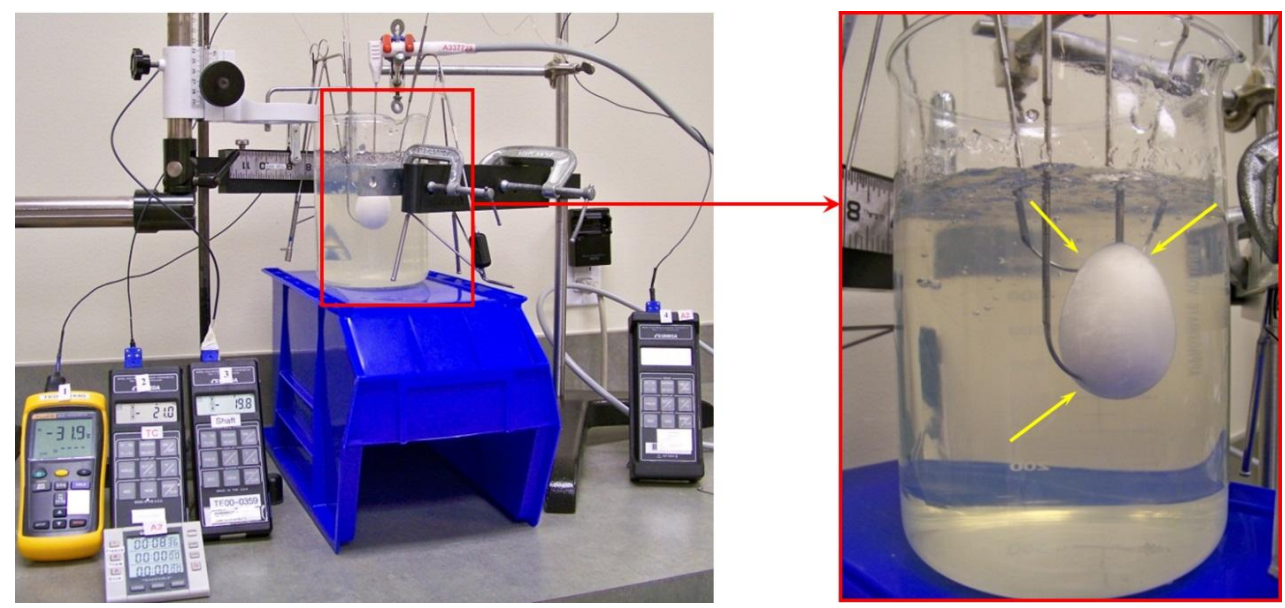

Fig. (1). Test setup used for the determination of the $-20^{\circ} \mathrm{C}$ and $-40^{\circ} \mathrm{C}$ isotherms (left) shown with magnified view of the iceball 
formation. Note: thermocouple insertion points indicated by yellow arrows.

Table 1. Summary of test parameters and sample sizes for all test groups.

\begin{tabular}{|c|c|c|c|c|c|}
\hline & & \multicolumn{2}{|c|}{ Manufacturer A } & \multicolumn{2}{c|}{ Manufacturer B } \\
\hline Procedure & Pressure [psi] & $\mathbf{1 . 7} \mathbf{~ m m}$ probe & $\mathbf{2 . 4} \mathbf{~ m m}$ probe & $\mathbf{1 . 4 7} \mathbf{~ m m}$ probe & $\mathbf{2 . 4} \mathbf{~ m m ~ p r o b e ~}$ \\
\hline \multirow{3}{*}{$\mathbf{F}(\mathbf{1 0})^{+}$} & $\mathbf{3 2 0 0}$ & $\mathrm{n}=3$ & $\mathrm{n}=3$ & $\mathrm{n}=3$ & $\mathrm{n}=3$ \\
\hline \multirow{3}{*}{ F-T-F (10-5-10) } & $\mathbf{3 0 0 0}$ & $\mathrm{n}=3$ & $\mathrm{n}=3$ & $\mathrm{n}=3$ & $\mathrm{n}=3$ \\
\cline { 2 - 6 } & $\mathbf{3 2 0 0}$ & $\mathrm{n}=3$ & $\mathrm{n}=3$ & $\mathrm{n}=3$ & $\mathrm{n}=3$ \\
\cline { 2 - 6 } & $\mathbf{3 4 5 0}$ & $\mathrm{n}=3$ & $\mathrm{n}=3$ & $\mathrm{n}=3$ & $\mathrm{n}=3$ \\
\hline
\end{tabular}

The resulting isotherm diameters and heights were evaluated using an equal variance student's t-test to determine the statistical significance between test groups. Differences between manufacturers, operating pressures, and freeze processes were compared between relevant test groups. JMP 9.0 (SAS Institute, Cary, NC) was used for the statistical analysis and a p-value $<0.05$ was used to indicate statically significant differences between test groups.

\section{RESULTS}

Average isotherm diameters and heights for all testing are provided in Tables 2, 3, respectively. A summary of the statistical analyses comparing isotherm dimensions between manufacturer, operating pressure, and freeze procedure is provided in Tables 3, 4 and $\mathbf{6}$, respectively.

Table 2. Average isotherm diameters for all tests.

\begin{tabular}{|c|c|c|c|c|c|c|}
\hline \multirow[b]{2}{*}{ Process } & \multirow[b]{2}{*}{ Pressure [psi] } & \multirow[b]{2}{*}{ Isotherm } & \multicolumn{2}{|c|}{ Manufacturer A } & \multicolumn{2}{|c|}{ Manufacturer B } \\
\hline & & & $1.7 \mathrm{~mm}$ probe & $2.4 \mathrm{~mm}$ probe & $1.47 \mathrm{~mm}$ probe & $2.4 \mathrm{~mm}$ probe \\
\hline \multirow{3}{*}{$\mathbf{F}$} & \multirow{3}{*}{3200} & $\mathbf{0}^{\circ} \mathrm{C}$ & $35.9 \pm 0.1$ & $37.4 \pm 0.9$ & $26.7 \pm 0.3$ & $33.8 \pm 1.3$ \\
\hline & & $-20^{\circ} \mathrm{C}$ & $22.4 \pm 0.9$ & $24.4 \pm 0.7$ & $12.8 \pm 0.1$ & $21.3 \pm 0.8$ \\
\hline & & $-40^{\circ} \mathrm{C}$ & $15.7 \pm 1.0$ & $19.0 \pm 1.8$ & $6.3 \pm 0.1$ & $14.3 \pm 0.7$ \\
\hline \multirow{9}{*}{ F-T-F } & \multirow{3}{*}{3000} & $\mathbf{0}^{\circ} \mathrm{C}$ & $45.6 \pm 0.6$ & $47.6 \pm 2.4$ & $34.0 \pm 0.6$ & $42.3 \pm 0.7$ \\
\hline & & $-20^{\circ} \mathrm{C}$ & $27.5 \pm 0.5$ & $29.3 \pm 2.6$ & $15.1 \pm 0.2$ & $23.4 \pm 0.8$ \\
\hline & & $-40^{\circ} \mathrm{C}$ & $18.7 \pm 0.6$ & $21.5 \pm 2.4$ & $7.8 \pm 0.2$ & $14.6 \pm 0.2$ \\
\hline & \multirow{3}{*}{3200} & $\mathbf{0}^{\circ} \mathrm{C}$ & $48.0 \pm 0.5$ & $48.7 \pm 0.2$ & $36.8 \pm 0.3$ & $35.2 \pm 0.2$ \\
\hline & & $-20^{\circ} \mathrm{C}$ & $28.7 \pm 0.5$ & $29.5 \pm 0.8$ & $16.5 \pm 0.4$ & $21.6 \pm 0.5$ \\
\hline & & $-40^{\circ} \mathrm{C}$ & $19.1 \pm 0.9$ & $21.6 \pm 0.9$ & $9.2 \pm 0.2$ & $14.7 \pm 0.6$ \\
\hline & \multirow{3}{*}{3450} & $\mathbf{0}^{\circ} \mathrm{C}$ & $47.7 \pm 0.4$ & $50.9 \pm 0.7$ & $38.2 \pm 0.4$ & $45.8 \pm 1.0$ \\
\hline & & $-20^{\circ} \mathrm{C}$ & $27.6 \pm 1.3$ & $30.9 \pm 0.6$ & $19.3 \pm 0.2$ & $29.0 \pm 0.7$ \\
\hline & & $-40^{\circ} \mathrm{C}$ & $19.1 \pm 0.5$ & $22.6 \pm 0.6$ & $11.3 \pm 0.2$ & $20.5 \pm 0.5$ \\
\hline
\end{tabular}

Table 3. Average isotherm heights for all tests.

\begin{tabular}{|c|c|c|c|c|c|c|}
\hline \multirow[b]{2}{*}{ Process } & \multirow[b]{2}{*}{ Pressure [psi] } & \multirow[b]{2}{*}{ Isotherm } & \multicolumn{2}{|c|}{ Manufacturer A } & \multicolumn{2}{|c|}{ Manufacturer B } \\
\hline & & & $1.7 \mathrm{~mm}$ probe & $2.4 \mathrm{~mm}$ probe & $1.47 \mathrm{~mm}$ probe & $2.4 \mathrm{~mm}$ probe \\
\hline \multirow{3}{*}{$\mathbf{F}$} & \multirow{3}{*}{3200} & $\mathbf{0}^{\circ} \mathrm{C}$ & $52.7 \pm 0.3$ & $53.9 \pm 1.6$ & $48.7 \pm 0.3$ & $50.8 \pm 0.8$ \\
\hline & & $-20^{\circ} \mathrm{C}$ & $41.1 \pm 0.1$ & $42.1 \pm 0.1$ & $38.6 \pm 0.2$ & $40.0 \pm 0.2$ \\
\hline & & $-40^{\circ} \mathrm{C}$ & $36.2 \pm 0.8$ & $37.2 \pm 0.5$ & $34.5 \pm 0.3$ & $34.4 \pm 0.0$ \\
\hline \multirow{9}{*}{ F-T-F } & \multirow{3}{*}{3000} & $\mathbf{0}^{\circ} \mathrm{C}$ & $61.2 \pm 0.4$ & $62.1 \pm 1.4$ & $53.4 \pm 0.6$ & $57.2 \pm 0.6$ \\
\hline & & $-20^{\circ} \mathrm{C}$ & $43.7 \pm 0.5$ & $44.6 \pm 0.4$ & $40.0 \pm 0.4$ & $40.9 \pm 0.4$ \\
\hline & & $-40^{\circ} \mathrm{C}$ & $37.6 \pm 1.2$ & $38.3 \pm 0.7$ & $36.4 \pm 0.5$ & $35.0 \pm 0.9$ \\
\hline & \multirow{3}{*}{3200} & $\mathbf{0}^{\circ} \mathrm{C}$ & $62.5 \pm 0.6$ & $60.1 \pm 2.1$ & $54.9 \pm 0.8$ & $52.1 \pm 0.3$ \\
\hline & & $-20^{\circ} \mathrm{C}$ & $46.1 \pm 0.8$ & $43.5 \pm 0.9$ & $41.1 \pm 0.6$ & $39.6 \pm 0.1$ \\
\hline & & $-40^{\circ} \mathrm{C}$ & $39.4 \pm 1.3$ & $38.1 \pm 0.5$ & $36.7 \pm 1.4$ & $34.5 \pm 0.8$ \\
\hline & \multirow{3}{*}{3450} & $\mathbf{0}^{\circ} \mathrm{C}$ & $63.6 \pm 1.0$ & $65.7 \pm 0.4$ & $56.0 \pm 0.0$ & $58.1 \pm 0.7$ \\
\hline & & $-20^{\circ} \mathrm{C}$ & $46.2 \pm 0.7$ & $48.8 \pm 0.7$ & + & + \\
\hline & & $-40^{\circ} \mathrm{C}$ & $40.3 \pm 0.8$ & $41.9 \pm 0.2$ & + & + \\
\hline
\end{tabular}

Isotherm height not measured. 


\subsection{Manufacturer Comparison}

The comparisons of isotherm sizes for the smaller and larger sized probes shown in Figs. (2). and (3)., respectively, show that Manufacturer A probes produced longer and wider isotherms at all three isotherm temperatures $\left(0^{\circ} \mathrm{C},-20^{\circ} \mathrm{C}\right.$, and $-40{ }^{\circ} \mathrm{C}$ ) relative to Manufacturer $\mathrm{B}$. This trend was consistent across all operating pressures and freeze procedures, and the observed differences in size were found to be statistically significant for all test cases excluding the comparison of the $-40{ }^{\circ} \mathrm{C}$ isotherms generated from multiple freeze processes at 3000 psi.

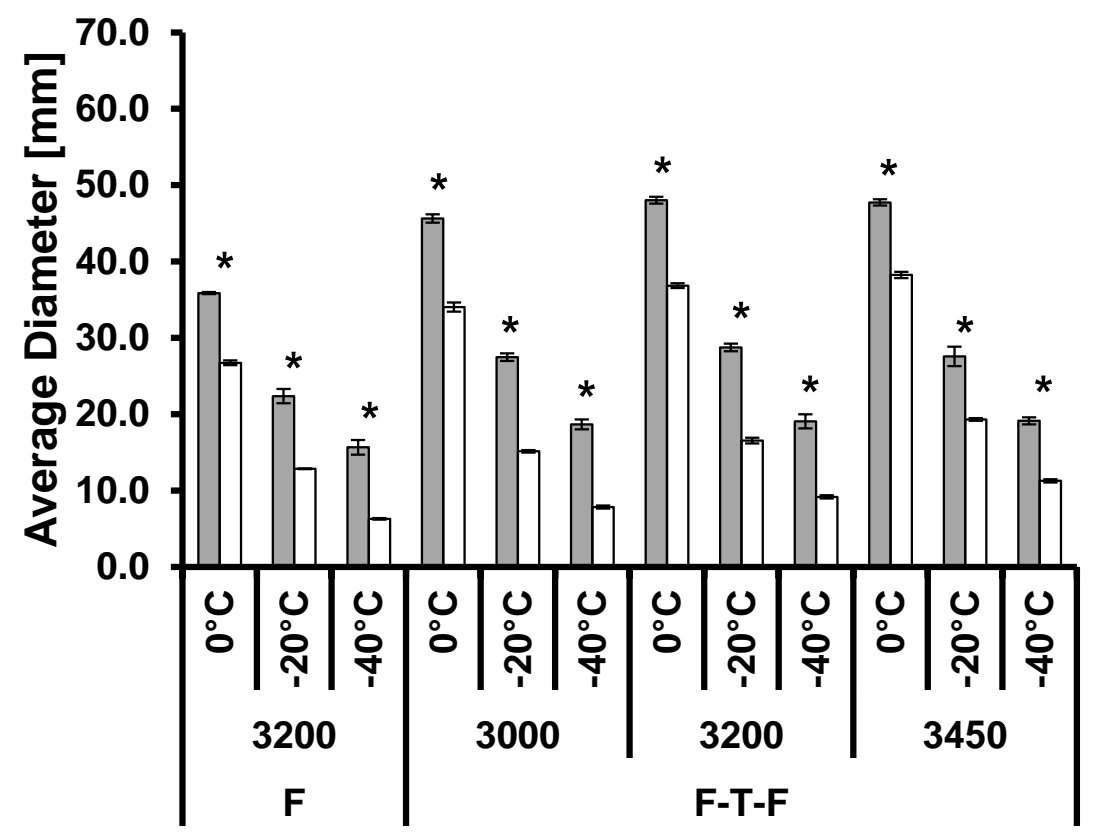

$\square$ Manuf. A - 1.7mm $\square$ Manuf. B - 1.47mm

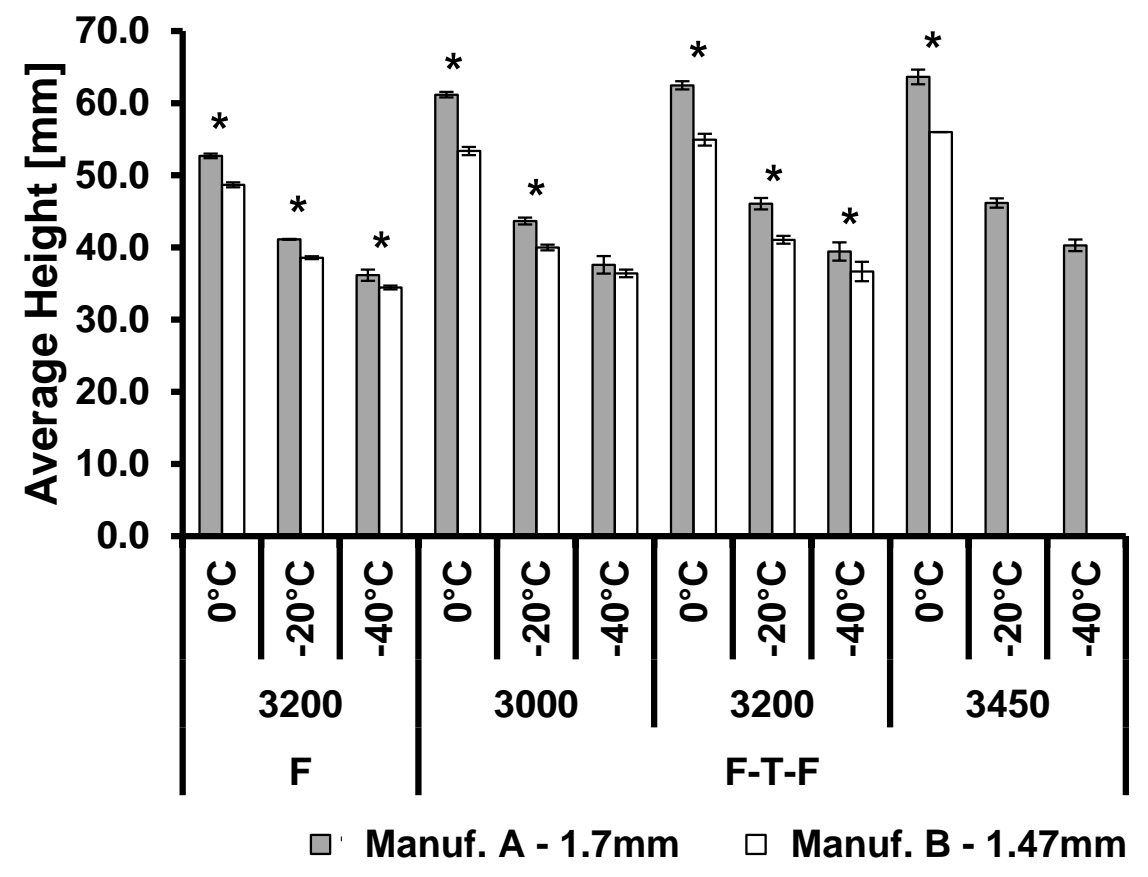

Fig. (2). Average isotherm diameter (top) and height (bottom) comparing isotherms by manufacturer after a single freeze (F) or freeze-thaw-freeze $(\mathrm{F}-\mathrm{T}-\mathrm{F})$ procedure at multiple operating pressures. Statistically significant differences $(\mathrm{p}<0.005)$ are indicated by an asterisk $(*)$. Note: error bars indicate one standard deviation. 

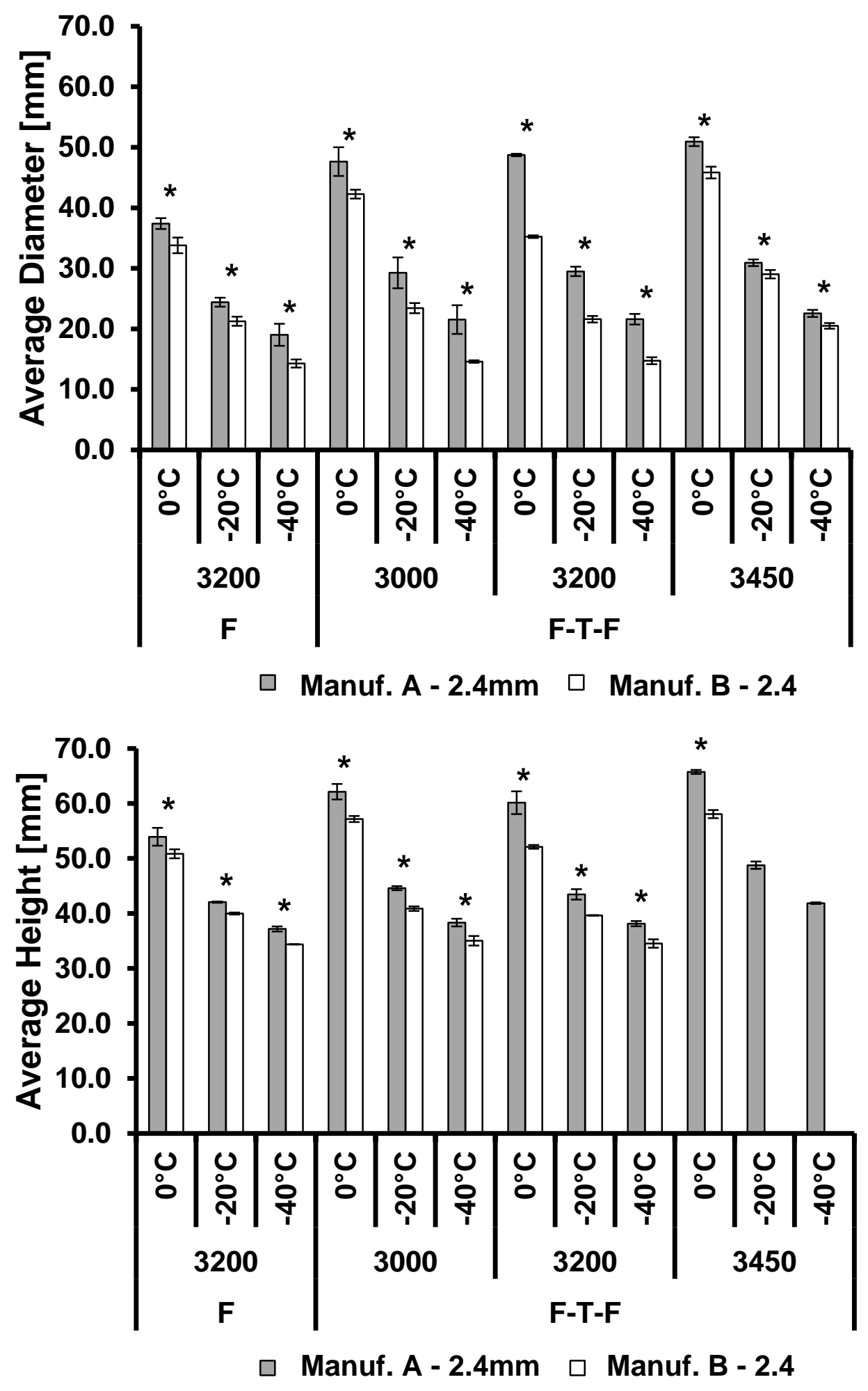

Fig. (3). Average isotherm diameter (top) and height (bottom) comparing isotherms by manufacturer after a single freeze (F) or freeze-thaw-freeze $(\mathrm{F}-\mathrm{T}-\mathrm{F})$ procedure at multiple operating pressures. Statistically significant differences $(\mathrm{p}<0.005)$ are indicated by an asterisk $(*)$. Note: error bars indicate one standard deviation. 
Table 4. Summary of p-values comparing isotherm sizes between manufacturers under identical operating conditions. Statistical significance $(\mathrm{p} \leq \mathbf{0 . 0 5})$ is indicated by an asterisk $(*)$.

\begin{tabular}{|c|c|c|c|c|c|}
\hline Comparison & Process & Pressure [psi] & Isotherm $\left[{ }^{\circ} \mathrm{C}\right]$ & Diameter & Height \\
\hline \multirow{12}{*}{$\begin{array}{c}\text { Manufacturer A } \\
1.7 \mathrm{~mm} \\
v s . \\
\text { Manufacturer B } \\
1.47 \mathrm{~mm}\end{array}$} & \multirow{3}{*}{$\mathbf{F}$} & \multirow{3}{*}{3200} & $\mathbf{0}$ & $<0.0001^{*}$ & $0.0009 *$ \\
\hline & & & -20 & $<0.0001^{*}$ & $<0.0001 *$ \\
\hline & & & -40 & $<0.0001^{*}$ & $0.0022 *$ \\
\hline & \multirow{9}{*}{ F-T-F } & \multirow{3}{*}{3000} & $\mathbf{0}$ & $<0.0001^{*}$ & $<0.0001^{*}$ \\
\hline & & & -20 & $<0.0001^{*}$ & $<0.0001 *$ \\
\hline & & & -40 & $<0.0001 *$ & 0.1279 \\
\hline & & \multirow{3}{*}{3200} & $\mathbf{0}$ & $<0.0001 *$ & $<0.0001^{*}$ \\
\hline & & & -20 & $<0.0001^{*}$ & $<0.0001^{*}$ \\
\hline & & & -40 & $<0.0001^{*}$ & $0.0110^{*}$ \\
\hline & & \multirow{3}{*}{3450} & $\mathbf{0}$ & $<0.0001^{*}$ & $<0.0001^{*}$ \\
\hline & & & -20 & $<0.0001^{*}$ & + \\
\hline & & & -40 & $<0.0001^{*}$ & + \\
\hline \multirow{12}{*}{$\begin{array}{c}\text { Manufacturer A } \\
2.4 \mathrm{~mm} \\
\text { vs. } \\
\text { Manufacturer B } \\
2.4 \mathrm{~mm}\end{array}$} & \multirow{3}{*}{$\mathbf{F}$} & \multirow{3}{*}{3200} & $\mathbf{0}$ & $<0.0001^{*}$ & $0.0038^{*}$ \\
\hline & & & -20 & $0.0006^{*}$ & $<0.0001 *$ \\
\hline & & & -40 & $0.0006^{*}$ & $<0.0001^{*}$ \\
\hline & \multirow{9}{*}{ F-T-F } & \multirow{3}{*}{3000} & $\mathbf{0}$ & $0.0010^{*}$ & $<0.0001^{*}$ \\
\hline & & & -20 & $0.0008^{*}$ & $<0.0001^{*}$ \\
\hline & & & -40 & $0.0001^{*}$ & $0.0016^{*}$ \\
\hline & & \multirow{3}{*}{3200} & $\mathbf{0}$ & $<0.0001^{*}$ & $<0.0001 *$ \\
\hline & & & -20 & $<0.0001^{*}$ & $0.0001 *$ \\
\hline & & & -40 & $<0.0001^{*}$ & $0.0027^{*}$ \\
\hline & & \multirow{3}{*}{3450} & $\mathbf{0}$ & $<0.0001 *$ & $<0.0001^{*}$ \\
\hline & & & -20 & $0.0178^{*}$ & + \\
\hline & & & -40 & $0.0005^{*}$ & + \\
\hline
\end{tabular}

+ Data for Manufacturer B probes not available, no comparisons were possible.

Table 5. Summary of p-values comparing isotherm sizes between single freeze (F) and multiple freeze (F-T-F) procedures at 3200 psi. Statistical significance $(p \leq 0.05)$ is indicated by an asterisk $(*)$.

\begin{tabular}{|c|c|c|c|c|c|}
\hline Comparison & Manufacturer & Probe Size & Isotherm $\left[{ }^{\circ} \mathrm{C}\right]$ & Diameter & Height \\
\hline \multirow{12}{*}{$\begin{array}{c}\text { Single Freeze }(\mathrm{F}) \\
\text { vs. } \\
\text { Freeze-thaw-freeze } \\
\text { (F-T-F) }\end{array}$} & \multirow{6}{*}{$\mathbf{A}$} & \multirow{3}{*}{$1.7 \mathrm{~mm}$} & 0 & $<0.0001^{*}$ & $<0.0001 *$ \\
\hline & & & -20 & $0.0005 *$ & $0.0004 *$ \\
\hline & & & -40 & $0.0125 *$ & $0.0190 *$ \\
\hline & & \multirow{3}{*}{$2.4 \mathrm{~mm}$} & 0 & $<0.0001 *$ & $0.0149 *$ \\
\hline & & & -20 & $0.0013 *$ & 0.0635 \\
\hline & & & -40 & 0.0893 & 0.0700 \\
\hline & \multirow{6}{*}{ B } & \multirow{3}{*}{$1.47 \mathrm{~mm}$} & 0 & $<0.0001 *$ & $0.0003 *$ \\
\hline & & & -20 & $<0.0001^{*}$ & $0.0018^{*}$ \\
\hline & & & -40 & $<0.0001^{*}$ & 0.0501 \\
\hline & & \multirow{3}{*}{$2.4 \mathrm{~mm}$} & 0 & 0.1324 & 0.0683 \\
\hline & & & -20 & 0.5592 & $0.0380^{*}$ \\
\hline & & & -40 & 0.4109 & 0.7254 \\
\hline
\end{tabular}

\subsection{Freeze Method Comparison}

As shown in Tables $\mathbf{4}$ and $\mathbf{5}$, the multiple freeze method produces larger isotherms than the single freeze method for all conditions excluding the height comparison of the $-20^{\circ} \mathrm{C}$ isotherm from Manufacturer B's $2.4 \mathrm{~mm}$ probe. Overall, changing the freeze method appears to produce more statistically significant differences in isotherm size for smaller probes than for larger probes, with a total of eleven out of twelve comparisons of height and diameter between methods being significant. Comparisons between larger probe sizes showed fewer statistically significant differences than those between smaller probes, and Manufacturer B showed fewer significant differences than Manufacturer A. 

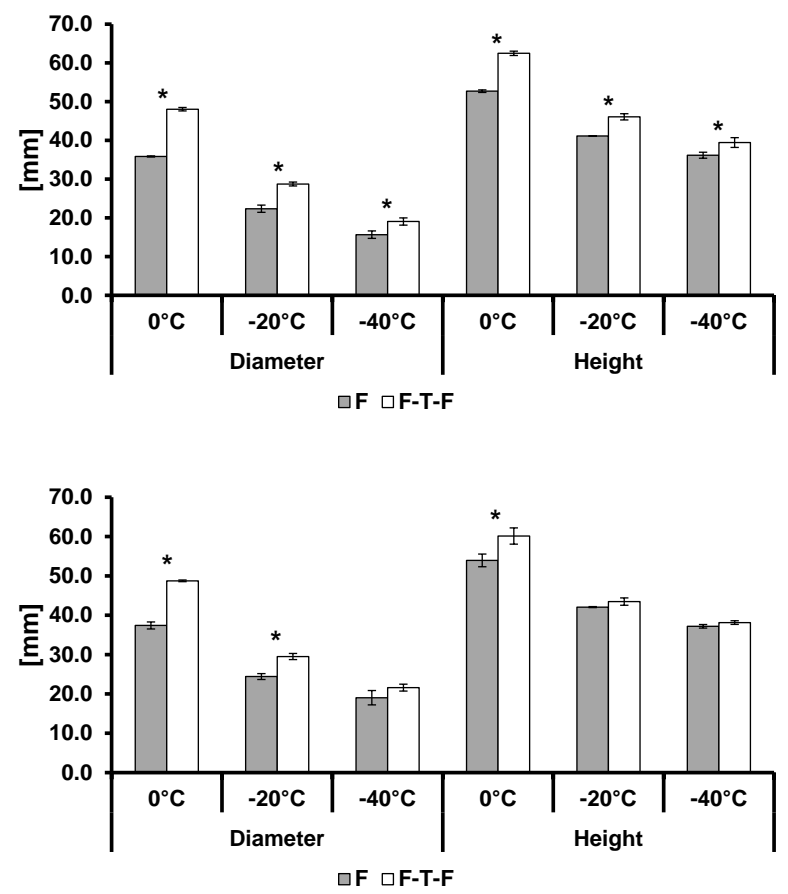

Fig. (4). Isotherm sizes for single freeze (F) and multiple freeze (F-T-F) procedures for the Manufacturer A $1.7 \mathrm{~mm}$ (top) and $2.4 \mathrm{~mm}$ (bottom) probe designs. Statistically significant differences $(\mathrm{p}<0.005)$ are indicated by an asterisk $(*)$. Note: error bars indicate one standard deviation.
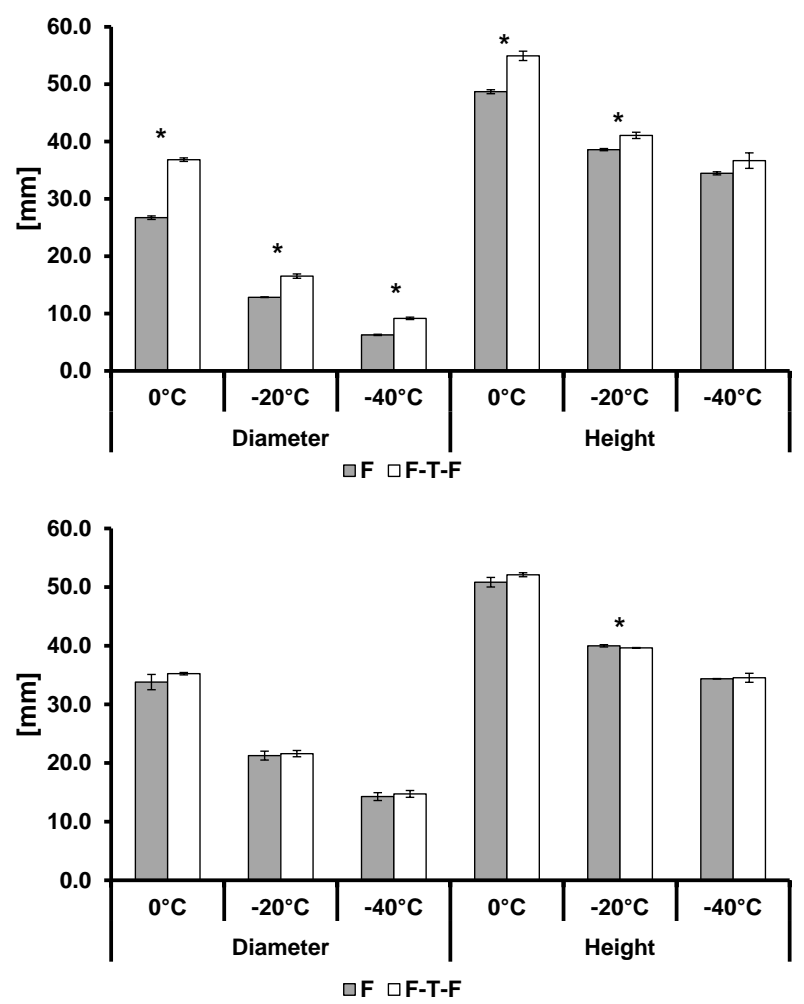

Fig. (5). Isotherm sizes for single freeze (F) and multiple freeze (F-T-F) procedures for the Manufacturer B $1.47 \mathrm{~mm}$ and $2.4 \mathrm{~mm}$ probe designs. Statistically significant comparisons are indicated by an asterisk $(*)$. Note: error bars indicate one standard deviation. 


\subsection{Operating Pressure Comparison}

Comparisons of isotherm sizes between operating pressures indicate that a consistent, significant correlation between isotherm size and operating pressure does not exist across the two manufacturers and for all isotherms. The most consistent trend when comparing results from the pressure conditions is that the 3450 psi condition resulted in a significantly larger $0{ }^{\circ} \mathrm{C}$ isotherm than the 3000 psi condition for all manufacturers and probe sizes, excluding the height of the $2.4 \mathrm{~mm}$ Manufacturer A probe. Test results from the $1.47 \mathrm{~mm}$ Manufacturer B probes show a positive correlation between operating pressure and isotherm size which is consistent and statistically significant for all comparisons between pressures excluding that comparison between 3200 and 3450 psi. Most of the $1.7 \mathrm{~mm}$ Manufacturer B probe results comparisons between pressures are also statistically significant, however, isotherm diameters and heights were observed to be smaller for the 3200 psi condition as compared to the 3000 psi condition, which contradicts the trend observed in the other comparisons. Results from Manufacturer A tests show a similar inconsistency when comparing all isotherm heights between pressures from the $2.4 \mathrm{~mm}$ probe design, with the 3200 psi condition producing smaller isotherms than the 3000 psi condition. As can be observed from Table 6, statistically significant differences between pressures were more prevalent for the Manufacturer B probes, whereas changes in operating pressure within a clinical operating range for Manufacturer A probes did not result in differences which were deemed to be statistically significant, overall.

Table 6. Summary of p-values comparing isotherm sizes between operating pressures for each manufacturer probe type. Statistical significance $(\mathbf{p} \leq \mathbf{0 . 0 5})$ is indicated by an asterisk $(*)$.

\begin{tabular}{|c|c|c|c|c|c|c|c|c|c|}
\hline \multirow[b]{3}{*}{ Comparison [psi] } & \multirow[b]{3}{*}{ Isotherm $\left[{ }^{\circ} \mathrm{C}\right]$} & \multicolumn{4}{|c|}{ Manufacturer A } & \multicolumn{4}{|c|}{ Manufacturer B } \\
\hline & & \multicolumn{2}{|c|}{$1.7 \mathrm{~mm}$ probe } & \multicolumn{2}{|c|}{$2.4 \mathrm{~mm}$ probe } & \multicolumn{2}{|c|}{$1.47 \mathrm{~mm}$ probe } & \multicolumn{2}{|c|}{$2.4 \mathrm{~mm}$ probe } \\
\hline & & Diameter & Height & Diameter & \begin{tabular}{|l|} 
Height \\
\end{tabular} & Diameter & Height & Diameter & Height \\
\hline \multirow{3}{*}{3000 vs. 3200} & 0 & $0.0008 *$ & 0.066 & 0.3852 & 0.1432 & $0.0003 *$ & $0.0158 *$ & $<0.0001 *$ & $<0.0001 *$ \\
\hline & -20 & 0.1152 & 0.0042 & 0.8619 & 0.0943 & $0.0005 *$ & - & $0.0183 *$ & - \\
\hline & -40 & 0.513 & 0.0901 & 0.9582 & 0.6394 & $0.0002 *$ & - & 0.7239 & - \\
\hline \multirow{3}{*}{3000 vs. 3450} & $\mathbf{0}$ & $0.0017 *$ & $0.0053^{*}$ & $0.0308^{*}$ & $0.0231 *$ & $<0.0001 *$ & $0.0014 *$ & $0.0009 *$ & 0.1002 \\
\hline & -20 & 0.8892 & 0.0034 & 0.2424 & $0.0003 *$ & $<0.0001 *$ & - & $<0.0001 *$ & - \\
\hline & -40 & 0.4483 & $0.0249 *$ & 0.4298 & $0.0001 *$ & $<0.0001 *$ & - & $<0.0001 *$ & - \\
\hline \multirow{3}{*}{3200 vs. 3450} & $\mathbf{0}$ & 0.4696 & 0.0906 & 0.1103 & $0.0033 *$ & $0.0093 *$ & 0.064 & $<0.0001 *$ & $<0.0001 *$ \\
\hline & -20 & 0.1409 & 0.858 & 0.3075 & $<0.0001 *$ & $<0.0001 *$ & - & $<0.0001 *$ & - \\
\hline & -40 & 0.9115 & 0.3769 & 0.4586 & $<0.0001^{*}$ & $<0.0001 *$ & - & $<0.0001 *$ & - \\
\hline
\end{tabular}

\section{DISCUSSION}

The size of isotherms generated during cryoablation requires physicians to carefully consider the selection of probes used to treat tumors. Industry practices for quantifying the size of isotherms in gelatin have been developed [16], but ex vivo and in vivo results have not been directly correlated to in vitro results. Despite the need to further develop in vitro techniques to accurately predict clinical performance, in vitro studies can still provide useful data when comparing device capabilities. Results of the testing conducted indicate that when considering variations in manufacturer, operating pressure, and freeze method, probe manufacturer may have the most consistent effect on the size of the isotherm. Statistically significant differences in isotherm height and diameter as a result of probe manufacturer were generated for all but one experimental comparison between manufacturers. Multiple freezes did result in larger isotherms in nearly all cases as opposed to single freezes, but these size differences were only significant in certain cases, seemingly more so for smaller probes. Differences in isotherm sizes due to operating pressure were the most prevalent between the highest (3450 psi) and lowest (3000 psi) operating pressures, but comparisons between 3000 psi and 3200 psi were inconsistent with other statistically significant trends. This could indicate that a correlation between isotherm size and operating pressure exists, but is less apparent within the standard range of clinical operating pressures used in this study [15].

\section{CONCLUSION}

The results of this study provide additional understanding of how equipment selection and surgical parameters may affect the size of kill zones. These results support the conclusion that similarly sized probes from two different manufacturers can significantly affect the resulting isotherms created during a procedure. This study also indicates that it may not be clinically feasible to generate kill zones of vastly different sizes only by modifying the probe operating 
pressure or freeze method. Instead, the use of a probe from a different manufacturer may be more effective if a different size zone is required. Furthermore, this study highlights the importance for manufacturers and clinicians alike to fully understand the size of thermal kill zones for each manufacturer case, and realize that implementation of the same sized probe from a different manufacturer could produce significantly different clinical results.

\section{CONFLICT OF INTEREST}

Exponent receives financial payment in exchange for consulting services from a variety of corporate, private, and government entities. Exponent's clients include companies which are involved in the design, manufacture, and distribution of medical devices. Exponent has received financial support from Endocare, Inc. for conducting portions of this study.

\section{ACKNOWLEDGEMENTS}

The authors would like to thank Endocare, Inc. for providing financial support for portions of this study.

\section{REFERENCES}

[1] A. Breda, J.S. Lam, S. Riggs, J.T. Leppert, D. Gui, J.W. Said, P.G. Schulam, and A.S. Belldegrun, "In vivo efficacy of laparoscopic assisted percutaneous renal cryotherapy: evidence based guidelines for the practicing urologist", J. Urol., vol. 179, no. 1, pp. 333-337, 2008. [http://dx.doi.org/10.1016/j.juro.2007.08.089] [PMID: 18006012]

[2] S.C. Campbell, V. Krishnamurthi, G. Chow, J. Hale, J. Myles, and A.C. Novick, "Renal cryosurgery: experimental evaluation of treatment parameters", Urology, vol. 52, no. 1, pp. 29-33, 1998.

[http://dx.doi.org/10.1016/S0090-4295(98)00169-1] [PMID: 9671865]

[3] J.L. Hinshaw, A.M. Shadid, S.Y. Nakada, S.P. Hedican, T.C. Winter III, and F.T. Lee Jr, "Comparison of percutaneous and laparoscopic cryoablation for the treatment of solid renal masses", AJR Am. J. Roentgenol., vol. 191, no. 4, pp. 1159-1168, 2008.

[http://dx.doi.org/10.2214/AJR.07.3706] [PMID: 18806159]

[4] C.C. Rupp, N.E. Hoffmann, F.R. Schmidlin, D.J. Swanlund, J.C. Bischof, and J.E. Coad, "Cryosurgical changes in the porcine kidney: histologic analysis with thermal history correlation", Cryobiology, vol. 45, no. 2, pp. 167-182, 2002. [http://dx.doi.org/10.1016/S0011-2240(02)00125-6] [PMID: 12482382]

[5] T.D. Atwell, M.R. Callstrom, M.A. Farrell, G.D. Schmit, D.A. Woodrum, B.C. Leibovich, G.K. Chow, D.E. Patterson, M.L. Blute, and J.W. Charboneau, "Percutaneous renal cryoablation: local control at mean 26 months of followup", J. Urol., vol. 184, no. 4, pp. 1291-1295, 2010. [http://dx.doi.org/10.1016/j.juro.2010.06.003] [PMID: 20719341]

[6] B. J. Donnelly, J. C. Saliken, P. M. Brasher, S. D. Ernst, J. C. Rewcastle, and H. Lau, "A randomized trial of external beam radiotherapy versus cryoablation in patients with localized prostate cancer", Cancer., vol. 116, pp. 323-330, 2010. [http://dx.doi.org/10.1002/cncr.24779]

[7] J.L. Hinshaw, and F.T. Lee Jr, "Cryoablation for liver cancer", Tech. Vasc. Interv. Radiol., vol. 10, no. 1, pp. $47-57,2007$. [http://dx.doi.org/10.1053/j.tvir.2007.08.005] [PMID: 17980318]

[8] J.S. Jones, J.C. Rewcastle, B.J. Donnelly, F.M. Lugnani, L.L. Pisters, and A.E. Katz, "Whole gland primary prostate cryoablation: initial results from the cryo on-line data registry", J. Urol., vol. 180, no. 2, pp. 554-558, 2008. [http://dx.doi.org/10.1016/j.juro.2008.04.027] [PMID: 18550117]

[9] H. Wang, P.J. Littrup, Y. Duan, Y. Zhang, H. Feng, and Z. Nie, "Thoracic masses treated with percutaneous cryotherapy: initial experience with more than 200 procedures", Radiology, vol. 235, no. 1, pp. 289-298, 2005. [http://dx.doi.org/10.1148/radiol.2351030747] [PMID: 15798173]

[10] A. Zemlyak, W.H. Moore, and T.V. Bilfinger, "Comparison of survival after sublobar resections and ablative therapies for stage I non-small cell lung cancer", J. Am. Coll. Surg., vol. 211, no. 1, pp. 68-72, 2010. [http://dx.doi.org/10.1016/j.jamcollsurg.2010.03.020] [PMID: 20610251]

[11] P.E. Davol, B.R. Fulmer, and D.B. Rukstalis, "Long-term results of cryoablation for renal cancer and complex renal masses", Urology, vol. 68, no. 1 Suppl, pp. 2-6, 2006. [http://dx.doi.org/10.1016/j.urology.2006.03.066] [PMID: 16857453]

[12] P.J. Littrup, B. Jallad, V. Vorugu, G. Littrup, B. Currier, M. George, and D. Herring, "Lethal isotherms of cryoablation in a phantom study: effects of heat load, probe size, and number", J. Vasc. Interv. Radiol., vol. 20, no. 10, pp. 1343-1351, 2009. [http://dx.doi.org/10.1016/j.jvir.2009.05.038] [PMID: 19695903]

[13] J.K. Seifert, C.D. Gerharz, F. Mattes, F. Nassir, K. Fachinger, C. Beil, and T. Junginger, "A pig model of hepatic cryotherapy. in vivo temperature distribution during freezing and histopathological changes", Cryobiology, vol. 47, no. 3, pp. 214-226, 2003. [http://dx.doi.org/10.1016/j.cryobiol.2003.10.007] [PMID: 14697733]

[14] B.K. Auge, R.W. Santa-Cruz, and T.J. Polascik, "Effect of freeze time during renal cryoablation: a swine model", J. Endourol., vol. 20, no. 12, pp. 1101-1105, 2006. [http://dx.doi.org/10.1089/end.2006.20.1101] [PMID: 17206911] 
[15] T. Mogami, J. Harada, K. Kishimoto, and S. Sumida, "Percutaneous MR-guided cryoablation for malignancies, with a focus on renal cell carcinoma", Int. J. Clin. Oncol., vol. 12, no. 2, pp. 79-84, 2007. [http://dx.doi.org/10.1007/s10147-006-0654-6] [PMID: 17443274]

[16] J.L. Young, S.B. Kolla, D.L. Pick, P. Sountoulides, O.G. Kaufmann, C.G. Ortiz-Vanderdys, V.B. Huynh, A.G. Kaplan, L.A. Andrade, K.E. Osann, M.K. Louie, E.M. McDougall, and R.V. Clayman, "In vitro, ex vivo and in vivo isotherms for renal cryotherapy", J. Urol., vol. 183, no. 2, pp. 752-758, 2010.

[http://dx.doi.org/10.1016/j.juro.2009.09.072] [PMID: 20022060]

(C) Rau et al. Licensee Bentham Open.

This is an open access article licensed under the terms of the Creative Commons Attribution-Non-Commercial 4.0 International Public License (CC BY-NC 4.0) (https://creativecommons.org/licenses/by-nc/4.0/legalcode), which permits unrestricted, non-commercial use, distribution and reproduction in any medium, provided the work is properly cited. 